OPEN ACCESS

Edited by:

Micaela Sgorbini,

University of Pisa, Italy

Reviewed by: Vincenzo Miragliotta,

University of Pisa, Italy

Gerald Fritz Schusser,

Leipzig University, Germany

${ }^{*}$ Correspondence:

Sushmitha S. Durgam

durgam.3@osu.edu

Specialty section:

This article was submitted to Comparative and Clinical Medicine,

a section of the journal

Frontiers in Veterinary Science

Received: 12 May 2020

Accepted: 29 June 2020

Published: 05 August 2020

Citation:

Sullivan SN, Altmann NN, Brokken MT and Durgam SS (2020) In vitro Effects

of Methylprednisolone Acetate on

Equine Deep Digital Flexor

Tendon-Derived Cells.

Front. Vet. Sci. 7:486.

doi: 10.3389/fvets.2020.00486

\section{In vitro Effects of Methylprednisolone Acetate on Equine Deep Digital Flexor Tendon-Derived Cells}

\author{
Stasia N. Sullivan, Nadine N. Altmann, Matthew T. Brokken and Sushmitha S. Durgam* \\ Department of Veterinary Clinical Sciences, College of Veterinary Medicine, The Ohio State University, Columbus, OH, \\ United States
}

Primary deep digital flexor tendon (DDFT) pathologies and those accompanying degenerative changes of navicular bone fibrocartilage are major causes of lameness associated with navicular disease. Intrasynovial corticosteroids are mainstay in the treatment due to the anti-inflammatory effects, but their effect on DDFT cell biosynthesis are unknown. The objective of this in-vitro study was to investigate the effects of methylprednisolone acetate (MPA) on cells isolated from the dorsal fibrocartilaginous region of forelimb DDFTs (DDFT-derived cells) of 5 horses (aged 11-17 years). Non-adherent aggregate cultures were established from third passage cells over a 72 to 96-h duration prior to treating with medium containing 0 (control), 0.05 and 0.5 $\mathrm{mg} / \mathrm{mL}$ MPA for $24 \mathrm{~h}$. Tendon and cartilage extracellular matrix (ECM) related gene expression, cell aggregate and culture medium GAG contents, culture medium collagen and MMP-3 and -13 concentrations were measured. After $24 \mathrm{~h}$ of treatment, only the higher MPA concentration $(0.5 \mathrm{mg} / \mathrm{mL})$ significantly down-regulated tendon ECM related genes; whereas, both MPA doses significantly down-regulated cartilage ECM related genes. MPA treatment did not affect the total GAG content of DDFT-derived cells or total GAG, soluble collagen and MMP-3 and-13 contents in culture medium compared to untreated controls. Future studies to determine the response of DDFT-derived cells with longer exposure times to corticosteroids and in the presence of inflammatory cytokines are necessary. These results are a first step in assessing the effects of intrasynovial medications on equine DDFT, for which currently no information exists.

Keywords: navicular disease, deep digital flexor tendon, methylprednisolone acetate, ECM mRNA expression, collagen, GAG, MMP-3/-13, horse

\section{INTRODUCTION}

Navicular disease is a common cause for performance-limiting forelimb lameness in horses. Primary deep digital flexor tendon (DDFT) pathologies and those accompanying degenerative changes of navicular bone fibrocartilage, distal interphalangeal joint and the adjacent peri-ligamentous structures are major causes of lameness associated with navicular syndrome (14). Medical treatments consisting of systemic NSAIDs, corrective farriery, and intra-synovial/intrabursal corticosteroid injections are commonly employed in the clinical management of horses with navicular disease (5-7). 
Distal interphalangeal joint and/or navicular bursa injections with corticosteroids, such as triamcinolone acetonide (TA) and methylprednisolone acetate (MPA), are mainstay in treating navicular horses due to their potent anti-inflammatory effects (5-10). In osteoarthritis therapy, intra-articular corticosteroid administration reduces synovitis and articular pain; however, corticosteroids can impair chondrocyte metabolism, resulting in altered extracellular matrix (ECM) composition and subsequent detrimental changes to articular cartilage structure (11-13). Although there is controversy regarding corticosteroidinduced positive (promote glycosaminoglycan (GAG) synthesis, improved cartilage scores) and negative (GAG degradation, cartilage disruption) metabolic effects on articular chondrocytes, recent studies suggest that the disparity in their effects can be attributed to dosage differences than the corticosteroid itself (11-13). Equimolar concentrations of TA and MPA have demonstrated similar effects on chondrocyte ECM transcriptional activity (14-16). While the in-vitro and in-vivo effects of corticosteroids on articular chondrocyte metabolism have been investigated, their effects on tendon cell biosynthesis are less known. A few studies utilizing human patellar tendon cells have demonstrated that dexamethasone and TA reduced collagen and proteoglycan secretion during in vitro culture (1720). Wei et al. showed that MPA injected into rat sub-acromion space increased collagen type I and type III mRNA expression of infraspinatus tendon tissue (21). To our knowledge, the effects of MPA on equine DDFT-derived cell biosynthetic activities have not been evaluated.

Improvement in advanced diagnostic imaging, primarily magnetic resonance imaging, has demonstrated that DDFT lesions varying from dorsal surface fibrillation, parasagittal splits extending to a variable depth, core lesions, and full-thickness disruption are amongst common pathologies seen in horses with navicular disease $(1-3,7,22)$. The DDFT structure at the navicular region is unique in that, it is composed of a superficial dorsal fibrocartilaginous layer, the deep dorsal layer (these 2 regions together constitute the longitudinal layer), and the palmar region comprised of circular collagen bundles. This heterogenous structure represents a functional adaptation of compressive loading from the adjacent navicular bone $(3,23)$. The cells within in the dorsal fibrocartilaginous zone of the DDFT are "rounded/chondrocyte-like" and secrete a proteoglycan-rich ECM relative to collagen and imparts compressive stiffness to this region $(23,24)$. Given that these cells synthesize ECM components and maintain tissue integrity, delineating the effects of corticosteroids on their ECM related gene expression and biosynthetic activities is necessary.

The objective of this in-vitro study was to investigate the effects of MPA on cells isolated from the dorsal fibrocartilaginous zone of the DDFT at the navicular region (DDFT-derived cells) under non-inflammatory conditions (3). Outcome measures associated with tissue metabolism, such as ECM related gene expression, glycosaminoglycan; GAG and collagen contents, degradation of ECM (MMP-3 and-13) were analyzed. We hypothesized that the concentrations of MPA utilized in this study will have deleterious effects on DDFT-derived cell compared to control DDFT-derived cells.

\section{MATERIALS AND METHODS}

Forelimb DDFTs were harvested from 5 horses undergoing euthanasia for reasons unrelated to this study. The horses included in this study were 2 mares and 3 geldings ( 3 Quarter horses, 1 Grade/mixed breed, 1 Hanoverian) between 11 and 17 years of age. All horses had a good body condition score $(\mathrm{BCS})>6 / 9$ and were free of forelimb lameness when trotted in-hand on smooth, hard surface. Horses were free of musculoskeletal abnormalities as determined through complete physical examination. The DDFT opposing the navicular bone was determined normal based on gross assessment at the time of harvesting tissue.

\section{DDFT Harvesting and Cell Isolation}

Immediately following euthanasia with sodium pentobarbital (150 mg/kg i.v.), both forelimb digits were disarticulated at the metacarpophalangeal joint. The hoof was cleaned, hair was clipped and the solar surface pared with a hoof knife. The feet were rinsed with water to remove gross debris and the entire digit was scrubbed with disinfectant solution. Each foot was disarticulated at the level of the distal interphalangeal joint to expose the proximal aspect of the navicular bone, without severing the DDFT. Using aseptic technique, the navicular bone was dissected en-bloc from the foot by transecting the surrounding soft tissues and set aside. The DDFT segment directly opposing the navicular bone and $0.5-\mathrm{cm}$ proximal (within the navicular bursa) was harvested using aseptic technique. The dorsal fibrocartilaginous region was dissected from the palmar portion, diced into $0.25 \mathrm{~cm}^{3}$ segments and digested in $0.15 \%$ collagenase II (Worthington, Lakewood, NJ) in DMEM supplemented with $2 \%$ fetal bovine serum (Gemini Biomedicals, Calabasas, CA) at $37^{\circ} \mathrm{C}$ overnight. Following digestion, the isolated cells were filtered through a 40-um filter (Thermo-Fisher, Waltham, MA). The cells were collected by centrifuging at $300 \times \mathrm{g}$ for $5 \mathrm{~min}$. The supernatant was removed, and the cell pellet was resuspended in culture medium containing Dulbecco's modified Eagle's medium containing 4.5 $\mathrm{g} / \mathrm{l}$ glucose and $300 \mu \mathrm{g} / \mathrm{mL}$ L-glutamine, supplemented with $10 \%$ fetal bovine serum, $100 \mathrm{U}$ sodium penicillin/mL and 100 $\mu \mathrm{g}$ streptomycin sulfate/mL (basal expansion medium). Cell yield was determined by use of a hemocytometer, and viability was estimated via trypan blue dye exclusion (Sigma, St. Louis, MO) (25).

\section{DDFT-Derived Cell Culture}

DDFT-derived cells were seeded at $5,000 \mathrm{cells} / \mathrm{cm}^{2}$ in monolayer cultures in basal expansion medium and maintained at $37^{\circ} \mathrm{C}$, $95 \%$ air $/ 5 \% \mathrm{CO}_{2}$ in a humidified incubator. Non-adherent cells were removed at day 2, the resulting colony forming units were trypsinized at day 7-9 and expanded in monolayers for two passages. Third passage DDFT-derived cells were used in subsequent experiments as described below. DDFT-derived cells were maintained as aggregate cultures to support their chondrogenic phenotype on the basis of results of another study and preliminary data collected in our laboratory (26). 


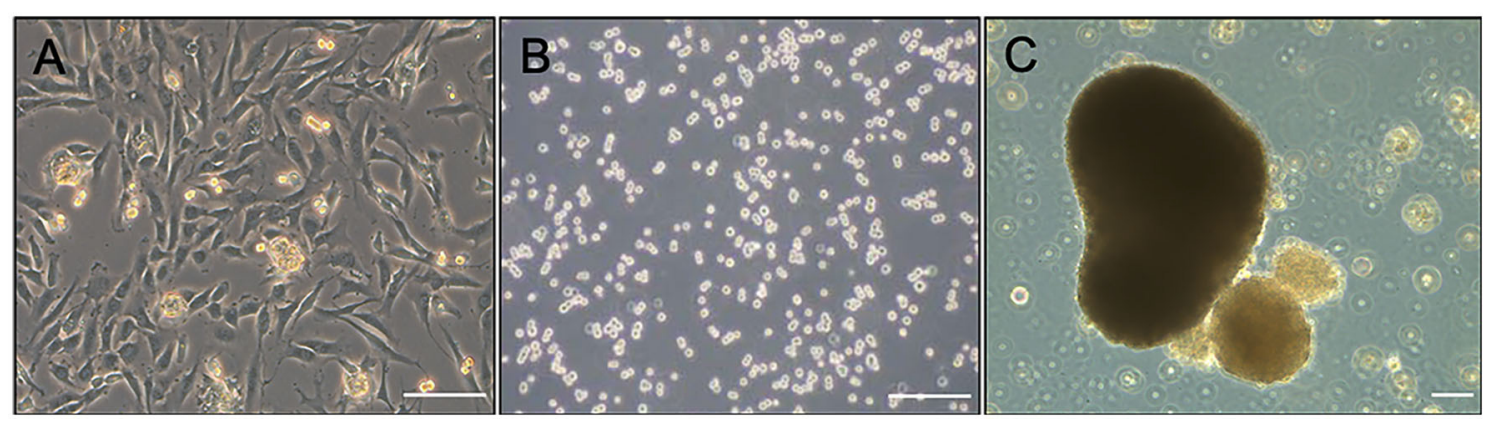

FIGURE 1 | (A) Photomicrograph of second passage DDFT-derived cell monolayer culture prior to trypsinization for aggregate culture. (B) Dispersed third passage DDFT-derived cells seeded in hydrogel-coated, Ultra Low attachment plates at the start of aggregate culture. (C) DDFT-derived cell aggregates formed in 72-96 h of non-adherent culture prior to MPA treatment. Scale bar: $100 \mu \mathrm{m}$.

\section{Aggregate Culture}

Aggregate cultures were established from third passage DDFTderived cells isolated from each individual horse (Figure 1A) by resuspending the cells in reduced serum medium (OptiMEM, Thermo-Fisher, Waltham, MA) supplemented with $50 \mu \mathrm{g} / \mathrm{mL}$ ascorbic acid, $100 \mathrm{U}$ sodium penicillin/mL, $100 \mu \mathrm{g}$ streptomycin sulfate $/ \mathrm{mL}, 1 \%$ insulin-transferrin-selenium and $2 \%$ fetal bovine serum (27). Cell suspensions containing a total of $3 \times 10^{6}$ cells and $0.5 \times 10^{6}$ cells were aliquoted into each well of a 6- and 24-well hydrogel-coated, Ultra Low Attachment plates, respectively (Corning Inc, Corning, NY) (Figure 1B). Cultures were maintained for $72-96 \mathrm{~h}$ while the floating cells formed gross and microscopically visible aggregates (Figure 1C) (27). Fresh medium was supplemented every $36-48 \mathrm{~h}$. Just prior to adding treatments, the medium was collected and frozen at $-80^{\circ} \mathrm{C}$ for later analysis of total soluble collagen and matrix metalloproteinase (MMP) contents. Treatment groups consisted of medium alone (control), medium $+0.05 \mathrm{mg} / \mathrm{mL}$ methylprednisolone acetate (0.05 MPA), or medium +0.5 $\mathrm{mg} / \mathrm{mL}$ MPA (0.5 MPA). After $24 \mathrm{~h}$ of incubation with the aforementioned treatment groups, the media and aggregates were collected separately, snap frozen in liquid nitrogen and stored at $-80^{\circ} \mathrm{C}$ for further analyses. The concentrations of MPA evaluated in this study were based on previous studies measuring corticosteroid-induced biosynthesis in equine chondrocytes (28, 29), corticosteroid dose divided by the average estimated volume of navicular bursa/distal interphalangeal joint $(8,30)$, and preliminary data collected in our laboratory.

\section{RNA Isolation and Quantitative RT-PCR}

Total RNA was isolated using a previously described protocol $(31,32)$. Cells from respective aggregate samples in 6-well plates were homogenized in a guanidinium thiocyanate-phenolchloroform solution reagent (TRIzol, ThermoFisher, Waltham, MA) according to manufacturer's suggested protocol. RNA purity and quantity were assessed spectrophotometrically (Nanodrop, ThermoFisher, Waltham, MA) on the basis of $\mathrm{A}_{260 / 280}$ measurement. Total RNA of $1 \mu \mathrm{g}$ was reverse-transcribed to cDNA which was used to measure the expression of cardinal cartilage ECM related markers (Sox9, collagen type II, aggrecan) and tendon ECM related genes (collagen type I, collagen type III, COMP) by SYBR green fluorescence-based RT-qPCR; all primer pairs were previously optimized for the mRNAs of interest (Table 1). A total of $10 \eta \mathrm{g}$ of cDNA template was utilized for each reaction. Each treatment group from individual horses were run as triplicates and threshold values from the triplicates were averaged prior to calculations. Expression of these genes in DDFT-derived cells treated with control, 0.05 and $0.5 \mathrm{MPA}$ were compared with the expression levels in third passage DDFTderived cells. Relative gene expression was quantified using the $2^{-\Delta \Delta C T}$ method, normalized to expression of the reference gene, elongation factor- $1 \alpha(\mathrm{EF} 1 \alpha)(33)$.

\section{Total Glycosaminoglycan (GAG) Content}

The cell aggregates from $0.5 \times 10^{6}$ DDFT-derived cells in control, 0.05 and 0.5 MPA treatment groups were individually digested in papain. Three replicates per treatment group per horse were used for this measurement. Total GAG content of representative aggregates and the culture treatment medium was determined through the use of a 1,9-dimethylmethylene blue binding assay $(31,34)$. All sample values were compared against a standard curve of chondroitin sulfate values to estimate the total GAG content in paired replicates.

\section{Total DNA Content}

Total DNA content was determined by fluorometric measurement of Hoechst 33258 (Sigma, St. Louis, MO) dye incorporation in DDFT-derived cell aggregates digested with papain that was utilized for GAG assay (31). All measurements (ug) were from $0.5 \times 10^{6}$ DDFT-derived cells in $0.5 \mathrm{~mL}$ of the respective culture medium.

\section{Total Soluble Collagen Content}

Total soluble collagen content in each treatment culture medium of DDFT-derived cell aggregates (three replicates per treatment per horse) was measured using a commercially available kit (Biocolor, Carrickfergus, County Antrim, UK) according to manufacturer's recommendations (35). All measurements (ng) were from $0.5 \times 10^{6}$ DDFT-derived cells in $0.5 \mathrm{~mL}$ of the respective culture medium. 
TABLE 1 | Primers for SYBRgreen RT-qPCR.

\begin{tabular}{|c|c|c|c|c|}
\hline Gene & $\begin{array}{l}\text { Accession } \\
\text { Number }\end{array}$ & & Sequence & $\begin{array}{l}\text { Amplicon } \\
\text { (bp) }\end{array}$ \\
\hline Coll & NC_009154 & $\begin{array}{l}S \\
A\end{array}$ & $\begin{array}{l}\text { 5' GAA AAC ATC CCA GCC AAG AA } \\
5^{\prime} \text { GAT TGC CAG TCT CCT CAT CC }\end{array}$ & 231 \\
\hline Col III & AW261123 & $\begin{array}{l}S \\
A\end{array}$ & $\begin{array}{l}\text { 5' AGG GGA CCT GGT TAC TGC TT } \\
5^{\prime} \text { TCT CTG GGT TGG GAC AGT CT }\end{array}$ & 215 \\
\hline COMP & NM_001081856 & $\begin{array}{l}S \\
A\end{array}$ & $\begin{array}{l}5^{\prime} \text { TCA TGT GGA AGC AGA TGG AG } \\
5^{\prime} \text { TAG GAA CCA GCG GTA GGA TG }\end{array}$ & 223 \\
\hline Col II & NM_001081764.1 & $\begin{array}{l}S \\
A\end{array}$ & $\begin{array}{l}\text { 5' AGC AGG AAT TTG GTG TGG AC } \\
5^{\prime} \text { TCT GCC CAG TTC AGG TCT CT }\end{array}$ & 223 \\
\hline Aggrecan & XM_023650277.1 & $\begin{array}{l}S \\
A\end{array}$ & $\begin{array}{l}\text { 5' GAC GCC GAG AGC AGG TGT } \\
5^{\prime} \text { AAG AAG TTG TCG GGC TGG Tा }\end{array}$ & 202 \\
\hline
\end{tabular}

\section{Medium MMP-3 and MMP-13 Activity}

Matrix metalloproteinase- 3 and -13 activity in treatment culture medium (three replicates per treatment per horse) were determined with commercially available ELISA kits (Quantikine, R\&D Systems, Minneapolis, MN) in accordance with the manufacturer's protocol. Briefly, the collected control, 0.05 or 0.5 MPA medium samples was combined with MMP-3 or MMP13 conjugates. The samples were washed and incubated with a substrate solution, and optical density was measured with a microplate reader set at $450 \mathrm{~nm}$.

\section{Statistical Analysis}

Normal distribution of data was assessed by Shapiro-Wilks test. Data were compared with one-way ANOVA (GAG) or the non-parametric equivalent, Kruskal-Wallis test on ranks (chondrocytic gene expression, tendon ECM gene expression, total soluble collagen, MMP-3 and-13). Post hoc comparisons for the detection of statistically significant differences between the control, 0.05 and $0.5 \mathrm{MPA}$ treatment groups were conducted with Tukey's method. Differences were considered statistically significant at $P<0.05$.

\section{RESULTS}

\section{Tendon ECM Related mRNA Expression}

Mean fold changes in mRNA expression with MPA treatments are depicted in Figure 2. 0.5 MPA treatment significantly decreased collagen type I and collagen type III mRNA compared to $0.05 \mathrm{MPA}$ (5-fold, $P=0.013 ; 4.5$-fold, $P=0.03$ ) and control (6.25-fold, $P=0.013$; 5-fold; $P=0.036$ ) treatments, respectively. Cartilage oligomeric matrix protein (COMP) mRNA was significantly decreased with $0.5 \mathrm{MPA}$ (8.3-fold, $P$ $=0.02$ ) treatment alone. Overall, $0.05 \mathrm{MPA}$ treatment did not significantly affect the tendon related ECM genes of DDFTderived cells compared to control.

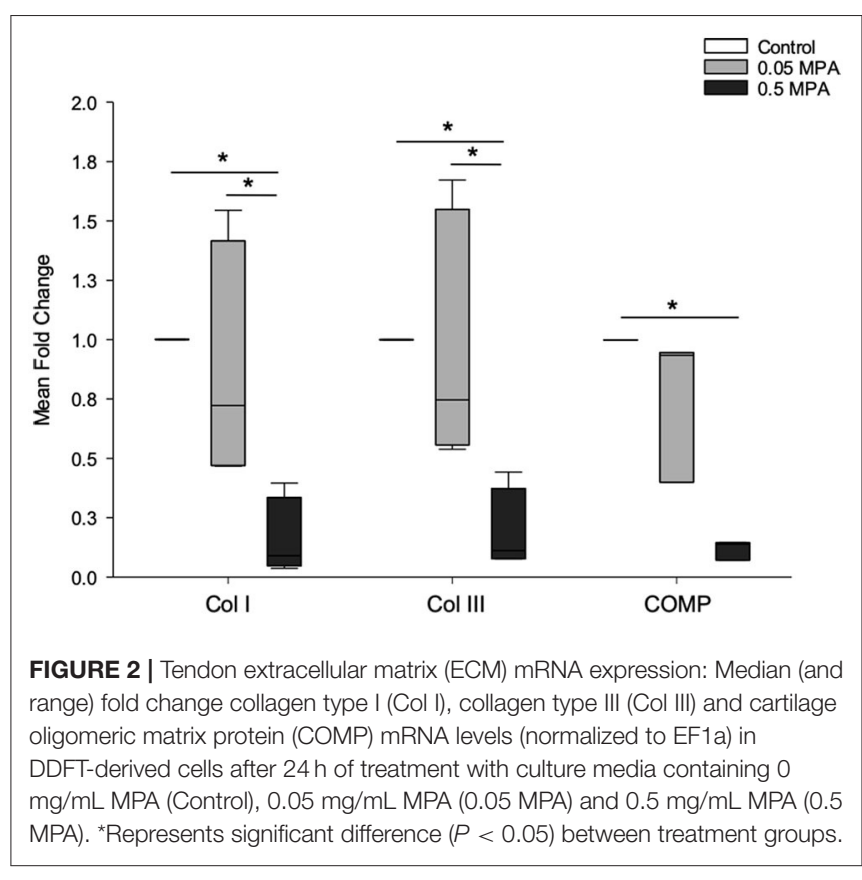

\section{Cartilage ECM Related mRNA Expression}

0.5 MPA treatment significantly decreased Sox-9, collagen type II and aggrecan mRNA expressions compared to 0.05 MPA (5-, 5.6-, 4.6-fold, $P=0.01,0.003,0.04)$ and control (4.5-, 10-, 7.6fold, $P=0.013,0.005,0.002$ ) treatments, respectively (Figure 3 ). In contrast to tendon ECM mRNAs, 0.05 MPA significantly decreased collagen type II and aggrecan mRNAs (2.1-, 1.8-fold, $P=0.015,0.02)$ compared to control. 0.05 MPA treatment did not significantly $(P=0.6)$ affect Sox -9 mRNA expression of DDFT-derived cells.

\section{GAG}

Control and MPA-treated DDFT-derived cell aggregates secreted small amounts of GAG (ug range) during in-vitro culture, and 


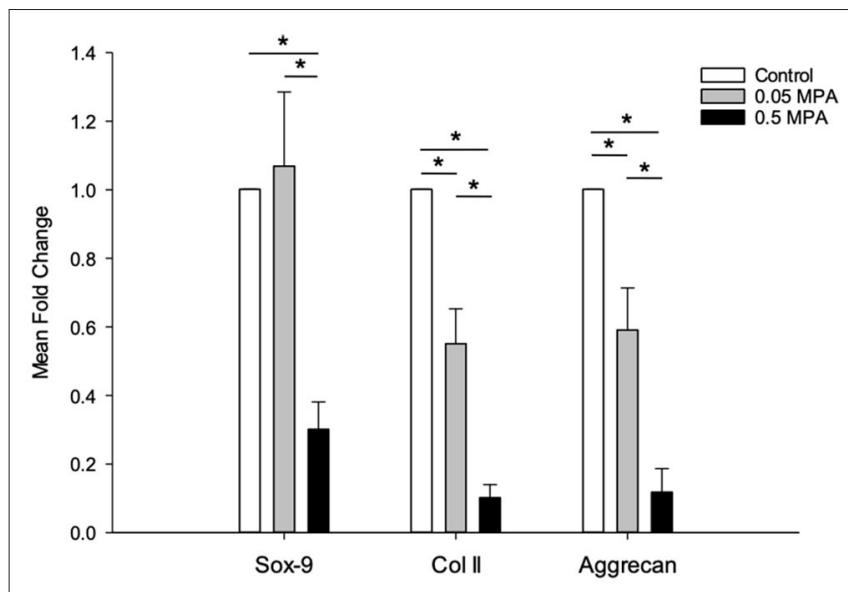

FIGURE 3 | Chondrocytic mRNA expression: Mean ( \pm standard deviation) fold change SRY-box transcription factor-9 (Sox-9), collagen type II (Col II) and aggrecan mRNA levels (normalized to EF1a) in DDFT-derived cells after $24 \mathrm{~h}$ of treatment with culture media containing $0 \mathrm{mg} / \mathrm{mL}$ MPA (Control), $0.05 \mathrm{mg} / \mathrm{mL}$ MPA (0.05 MPA) and $0.5 \mathrm{mg} / \mathrm{mL}$ MPA (0.5 MPA). *Represents significant difference $(P<0.05)$ between treatment groups.

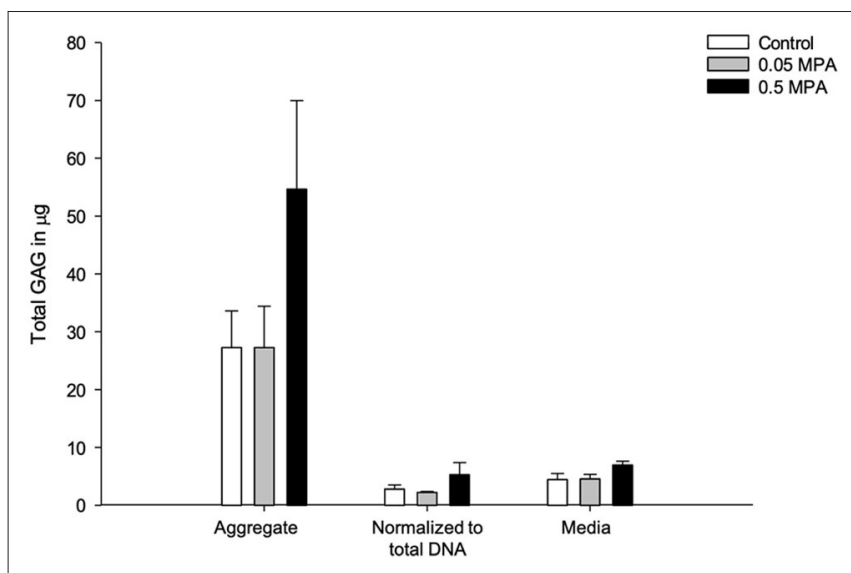

FIGURE 4 | Mean ( \pm standard deviation) glycosaminoglycan (GAG) content (ug) in DDFT-derived cell aggregates, aggregate normalized to total DNA and culture media after $24 \mathrm{~h}$ of treatment with $0 \mathrm{mg} / \mathrm{mL}$ MPA (Control), 0.05 $\mathrm{mg} / \mathrm{mL}$ MPA (0.05 MPA) and $0.5 \mathrm{mg} / \mathrm{mL}$ MPA (0.5 MPA).

was predominantly retained within the aggregates (Figure 4). There was no significant difference $(P=0.182)$ in the total GAG contents of control, 0.05 and 0.5 MPA treated DDFT-derived cell aggregates. This finding remained consistent $(P=0.283)$ when the total GAG content was normalized to cell number (total DNA content). There was no significant difference $(P=0.182)$ in the GAG content released into culture medium of control, 0.05 and 0.5 MPA DDFT-derived cell aggregates.

\section{Total Soluble Collagen}

There was no significant difference $(P=0.6)$ in the total soluble collagen concentrations of culture medium from control, 0.05 and 0.5 MPA treated DDFT-derived cells (Table 2).

\section{MMP-3 and MMP-13}

There were no significant differences in the culture medium MMP-3 and MMP-13 concentrations of control, 0.05 and 0.5 MPA treated DDFT-derived cell aggregates (Table 2).

\section{DISCUSSION}

This study's hypothesis that in vitro MPA treatment of DDFT-derived cells under non-inflammatory conditions will have negative effects on outcome measures evaluating ECM metabolism was largely not supported by the results of this study. Although MPA treatment of DDFT-derived cells significantly down-regulated tendon and cartilage ECM related genes, ECM metabolism evaluated through culture medium GAG, collagen, MMP-3 and-13 contents was unaffected by MPA treatment. Due to the marked heterogeneity in endogenous cells of DDFT at the navicular region, passage 3 cells isolated from the dorsal fibrocartilaginous region were utilized for all analyses. Given their rounded, chondrocyte-like in vivo morphology, DDFTderived cells were cultured as non-adherent aggregates for 72$96 \mathrm{~h}$ prior to MPA treatment. These cells readily aggregated during in vitro culture.

Our results demonstrate that after $24 \mathrm{~h}$ of treatment, only the higher MPA concentration $(0.5 \mathrm{mg} / \mathrm{mL})$ significantly downregulated tendon ECM relates genes; whereas, both MPA doses significantly down-regulated cartilage ECM related genes. Tendon and cartilage ECM related genes were evaluated given the fibrocartilaginous ECM within the DDFT at this location. Corticosteroid effects on tendon cell transcriptional activities have been minimally investigated. Triamcinolone and dexamethasone decreased collagen and proteoglycan secretion of normal human patellar tenocytes (17-19); however, these studies did not evaluate the changes in ECM transcript levels. In vivo, Wei et al. showed that peritendinous MPA injection in normal and injured rat supraspinatus tendon upregulated collagen type I and type III mRNA by 4 - to 5-fold (21). Although these studies collectively represent corticosteroid effects on tendon cells, the outcomes reported are not analogous to the equine DDFT given their distinct structural-cellular characteristics. Our findings of down-regulated ECM related genes in MPA-treated DDFTderived cells is more consistent with normal and interleukin$1 \beta$ inflamed equine cartilage and articular chondrocytes treated with MPA $(16,36)$. Further research investigating the differential down-regulation of tendon and cartilage ECM related genes observed in this study is warranted.

MPA treatment did not affect the total soluble collagen content in culture medium, total GAG content of DDFTderived cells or GAG released into culture medium compared to untreated controls. It should be noted that culture medium collagen and GAG contents measured via standard colorimetric absorbance assays were small, and represents the cumulative sum throughout the aggregate culture duration. It is possible that subtle differences following MPA treatment may have been masked given the assay techniques used here. Other studies that have documented decreased collagen and proteoglycan synthesis in human tenocytes, equine cartilage explants and articular 


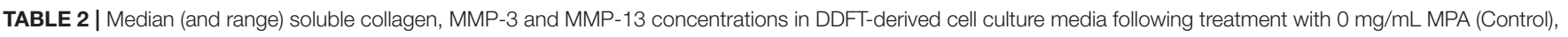
$0.05 \mathrm{mg} / \mathrm{mL}$ MPA (0.05 MPA) and $0.5 \mathrm{mg} / \mathrm{mL}$ MPA (0.5 MPA).

\begin{tabular}{|c|c|c|c|c|}
\hline Median; range & Control & 0.05 MPA & 0.5 MPA & $P$-value \\
\hline $\begin{array}{l}\text { Soluble collagen } \\
\text { (nanograms/mL) }\end{array}$ & 244 (235-343) & 240 (236-308) & 254 (237-348) & 0.9 \\
\hline $\begin{array}{l}\text { MMP-3 } \\
\text { (nanograms/mL) }\end{array}$ & $0.62(0.62-0.65)$ & $0.63(0.62-0.64)$ & $0.63(0.62-0.65)$ & 0.6 \\
\hline $\begin{array}{l}\text { MMP-13 } \\
\text { (picograms/mL) }\end{array}$ & 3.32 (3.31-3.32) & 3.34 (3.33-3.36) & $3.36(3.35-3.38)$ & 0.6 \\
\hline
\end{tabular}

chondrocytes following triamcinolone and MPA treatments utilized ${ }^{3} \mathrm{H}$-proline and ${ }^{35} \mathrm{SO}_{4}$ incorporation assays (17-19, 28, 29). Given the low biosynthetic capacities of DDFT-derived cells observed during in vitro culture, further dissecting the effect of MPA treatment with radioisotope studies and at longer exposure times are necessary.

Clinical studies have demonstrated transient pain relief and improvement of function following intrasynovial injections in navicular horses $(5,37)$; however, negative sequelae such as tendon degeneration and rupture have been reported $(21,38)$. Matrix metalloproteinase (MMP) proteins are involved in tendon ECM breakdown during remodeling in homeostasis and healing and are synthesized by tendon cells, fibroblasts and leukocytes $(39,40)$. MMP-3 is a potent proteoglycan-degrading enzyme, plays a major role in degrading collagen, fibronectin, elastin and laminin and activates other MMPs such as MMP-1,-7,-9, and-13. Our results show that MPA treatment did not affect the MMP activity of DDFT-derived cells and is likely due to the non-inflammatory culture conditions utilized in this study. MMP-3 expression in normal tendon tissue is low (41). In tendon injury, in vitro studies have demonstrated increased (42), decreased (20) or no changes (43) in tissue MMP expression. In vivo peritendinous triamcinolone and prednisolone injection in rat Achilles tendon induced MMP-3 expression, tendon cell apoptosis and collagen attenuation (41). Overall our understanding of corticosteroid-induced changes in tendon MMP activity is preliminary and delineating these mechanisms may shed light on structural and functional tendon damage that can occur secondary to corticosteroid administration.

This in vitro study has several limitations. The low $(n=$ 5) number of horses included combined with low in vitro biosynthetic capacity of DDFT-derived cells may have precluded detection of small differences among groups. The lack of an effect by MPA on collagen, proteoglycan contents and MMP production of DDFT-derived cells is likely due to the noninflammatory culture conditions utilized in this study; similar to the findings of a few studies assessing corticosteroid effects in normal cartilage and chondrocytes $(28,29)$. It is also not known whether clinically evident DDFT pathology existing in most horses with navicular disease alters sensitivity to corticosteroidmediated sequalae. Lastly, DDFT-derived cell responses to MPA were only investigated at the 24-h timepoint, and therefore, temporal changes at later timepoints were not evaluated.
Results of this study demonstrate that MPA treatment (concentrations in the range of $10^{-5} \mathrm{M}$ ) downregulated ECM related gene expression of equine DDFT-derived cells maintained under non-inflammatory conditions; however, collagen, GAG and MMP contents measured in the culture medium were unchanged. Further studies to assess these responses in the presence of inflammatory cytokines are warranted. While accepting that tissue-level responses under the influence of biomechanical stressors may be different, this is a first step is assessing the effects of intrasynovial medications on equine DDFT for which currently no information exists. These results serve as a foundation for further in vitro and in vivo studies, and subsequent clinical recommendations.

\section{DATA AVAILABILITY STATEMENT}

The datasets presented in this study can be found in online repositories. The names of the repository/repositories and accession number(s) can be found in the article/supplementary material.

\section{ETHICS STATEMENT}

The tendon samples utilized in this study were obtained after euthanizing horses for unrelated reasons and from horses donated to the university for research purposes. As such, an ethical review process specific to this study was not required.

\section{AUTHOR CONTRIBUTIONS}

SS and SD conducted experiments and analyzed the data. NA contributed to the acquisition, analysis and interpreted the data. $\mathrm{SD}$ conceived the study design and obtained funding for the study. All authors wrote, critically revised the manuscript for intellectual content, and approved the final submitted version of the manuscript.

\section{FUNDING}

Funding was obtained from the Ohio State University Equine Research Fund by the Ohio State Racing Commission. 


\section{REFERENCES}

1. Murray RC, Schramme MC, Dyson SJ, Branch MV, Blunden TS. Magnetic resonance imaging characteristics of the foot in horses with palmar foot pain and control horses. Vet Radiol Ultrasound. (2006) 47:116. doi: 10.1111/j.1740-8261.2005.00100.x

2. Blunden A, Murray R, Dyson S. Lesions of the deep digital flexor tendon in the digit: a correlative MRI and post mortem study in control and lame horses. Equine Vet J. (2009) 41:25-33. doi: 10.2746/042516408X343028

3. Blunden A, Dyson S, Murray R, Schramme M. Histopathology in horses with chronic palmar foot pain and age-matched controls. Part 2: the deep digital flexor tendon. Equine Vet J. (2006) 38:23-7. doi: 10.2746/042516406775374342

4. Blunden A, Dyson S, Murray R, Schramme M. Histopathology in horses with chronic palmar foot pain and age-matched controls. Part 1: navicular bone and related structures. Equine Vet J. (2006) 38:1522. doi: $10.2746 / 042516406775374298$

5. Marsh CA, Schneider RK, Sampson SN, Roberts GD. Response to injection of the navicular bursa with corticosteroid and hyaluronan following high-field magnetic resonance imaging in horses with signs of navicular syndrome: 101 cases (2000-2008). J Am Vet Med Assoc. (2012) 241:135364. doi: 10.2460/javma.241.10.1353

6. de Grauw JC, Visser-Meijer MC, Lashley F, Meeus P, van Weeren RP. Intraarticular treatment with triamcinolone compared with triamcinolone with hyaluronate: A randomised open-label multicentre clinical trial in 80 lame horses. Equine Vet J. (2016) 48:152-8. doi: 10.1111/evj.12383

7. Gutierrez-Nibeyro SD, White Ii NA, Werpy NM. Outcome of medical treatment for horses with foot pain: 56 cases. Equine Vet J. (2010) 42:6805. doi: 10.1111/j.2042-3306.2010.00081.x

8. Manfredi JM, Boyce M, Malone ED, Anderson C, Anderson LB, Trumble TN. Steroid diffusion into the navicular bursa occurs in horses affected by palmar foot pain. Vet Rec. (2012) 171:642. doi: 10.1136/vr.101075

9. Boyce M, Malone ED, Anderson LB, Park S, Godden SM, Jenner F, et al. Evaluation of diffusion of triamcinolone acetonide from the distal interphalangeal joint into the navicular bursa in horses. Am J Vet Res. (2010) 71:169-75. doi: 10.2460/ajvr.71.2.169

10. Pauwels FE, Schumacher J, Castro FA, Holder TE, Carroll RC, Sega GA, et al. Evaluation of the diffusion of corticosteroids between the distal interphalangeal joint and navicular bursa in horses. Am J Vet Res. (2008) 69:611-6. doi: 10.2460/ajvr.69.5.611

11. Kawcak CE, Norrdin RW, Frisbie DD, Trotter GW, Mcilwraith CW. Effects of osteochondral fragmentation and intra-articular triamcinolone acetonide treatment on subchondral bone in the equine carpus. Equine Vet J. (1998) 30:66-71. doi: 10.1111/j.2042-3306.1998.tb04090.x

12. Frisbie DD, Kawcak CE, Baxter GM, Trotter GW, Powers BE, Lassen ED, et al. Effects of 6alpha-methylprednisolone acetate on an equine osteochondral fragment exercise model. Am J Vet Res. (1998) 59:1619-28.

13. Frisbie DD, Kawcak CE, Trotter GW, Powers BE, Walton RM, McIlwraith CW. Effects of triamcinolone acetonide on an in vivo equine osteochondral fragment exercise model. Equine Vet J. (1997) 29:349-59. doi: 10.1111/j.2042-3306.1997.tb03138.x

14. Richardson DW, Dodge GR. Dose-dependent effects of corticosteroids on the expression of matrix-related genes in normal and cytokine-treated articular chondrocytes. Inflamm Res. (2003) 52:39-49. doi: 10.1007/s000110300012

15. Busschers E, Holt JP, Richardson DW. Effects of glucocorticoids and interleukin-1 beta on expression and activity of aggrecanases in equine chondrocytes. Am J Vet Res. (2010) 71:176-85. doi: 10.2460/ajvr.71.2.176

16. Dechant JE, Baxter GM, Frisbie DD, Trotter GW, McIlwraith CW. Effects of dosage titration of methylprednisolone acetate and triamcinolone acetonide on interleukin-1-conditioned equine articular cartilage explants in vitro. Equine Vet J. (2003) 35:444-50. doi: 10.2746/042516403775600479

17. Wong MW, Tang YY, Lee SK, Fu BS. Glucocorticoids suppress proteoglycan production by human tenocytes. Acta Orthop. (2005) 76:927-31. doi: 10.1080/17453670610046118

18. Wong MW, Tang YN, Fu SC, Lee KM, Chan KM. Triamcinolone suppresses human tenocyte cellular activity and collagen synthesis. Clin Orthop Relat Res. (2004) 421:277-81. doi: 10.1097/01.blo.0000118184.83983.65
19. Wong MW, Tang YY, Lee SK, Fu BS, Chan BP, Chan CK. Effect of dexamethasone on cultured human tenocytes and its reversibility by platelet-derived growth factor. J Bone Joint Surg Am. (2003) 85:191420. doi: 10.2106/00004623-200310000-00008

20. Tempfer H, Gehwolf R, Lehner C, Wagner A, Mtsariashvili M, Bauer HC, et al. Effects of crystalline glucocorticoid triamcinolone acetonide on cultered human supraspinatus tendon cells. Acta Orthop. (2009) 80:35762. doi: 10.3109/17453670902988360

21. Wei AS, Callaci JJ, Juknelis D, Marra G, Tonino P, Freedman KB, et al. The effect of corticosteroid on collagen expression in injured rotator cuff tendon. $J$ Bone Joint Surg Am. (2006) 88:1331-8. doi: 10.2106/JBJS.E.00806

22. Sherlock C, Mair T, Blunden T. Deep erosions of the palmar aspect of the navicular bone diagnosed by standing magnetic resonance imaging. Equine Vet J. (2008) 40:684-92. doi: 10.2746/042516408X330365

23. Beck S, Blunden T, Dyson S, Murray R. Are matrix and vascular changes involved in the pathogenesis of deep digital flexor tendon injury in the horse? Vet J. (2011) 189:289-95. doi: 10.1016/j.tvjl.2010.07.015

24. Vogel KG. Tendon structure and response to changing mechanical load. $J$ Musculoskel Neuron Interact. (2003) 3:323-5.

25. Durgam SS, Stewart AA, Pondenis HC, Gutierrez-Nibeyro SM, Evans RB, Stewart MC. Comparison of equine tendon- and bone marrow-derived cells cultured on tendon matrix with or without insulin-like growth factor-I supplementation. Am J Vet Res. (2012) 73:153-61. doi: 10.2460/ajvr.73.1.153

26. Quam V, Altmann N, coughlin H, Brokken M, Durgam S. Tendon progenitor cells isolated from equine deep digital flexor tendon at the navicular region are restricted to a chondrogenic phenotype. In: American College of Veterinary Surgeons. Veterinary Surgery. Las Vegas, NV (2019).

27. Stewart MC, Saunders KM, Burton-Wurster N, Macleod JN. Phenotypic stability of articular chondrocytes in vitro: the effects of culture models, bone morphogenetic protein 2, serum supplementation. J Bone Miner Res. (2000) 15:166-74. doi: 10.1359/jbmr.2000.15.1.166

28. Yates AC, Stewart AA, Byron CR, Pondenis HC, Kaufmann KM, Constable PD. Effects of sodium hyaluronate and methylprednisolone acetate on proteoglycan metabolism in equine articular chondrocytes treated with interleukin-1. Am J Vet Res. (2006) 67:1980-6. doi: 10.2460/ajvr.67.12.1980

29. Byron CR, Benson BM, Stewart AA, Pondenis HC. Effects of methylprednisolone acetate and glucosamine on proteoglycan production by equine chondrocytes in vitro. Am J Vet Res. (2008) 69:1123-8. doi: 10.2460/ajvr.69.9.1123

30. Edmonds RE, Garvican ER, Smith RK, Dudhia J. Influence of commonly used pharmaceutical agents on equine bone marrow-derived mesenchymal stem cell viability. Equine Vet J. (2017) 49:352-7. doi: 10.1111/evj.12590

31. Durgam S, Schuster B, Cymerman A, Stewart A, Stewart M. Differential adhesion selection for enrichment of tendon-derived progenitor cells during in vitro culture. Tissue Eng Part C Methods. (2016) 22:8018. doi: $10.1089 /$ ten.tec. 2016.0152

32. Durgam SS, Stewart AA, Pondenis HC, Yates AC, Evans RB, Stewart MC. Responses of equine tendon- and bone marrow-derived cells to monolayer expansion with fibroblast growth factor-2 and sequential culture with pulverized tendon and insulin-like growth factor-I. Am J Vet Res. (2012) 73:162-70. doi: 10.2460/ajvr.73.1.162

33. Livak KJ, Schmittgen TD. Analysis of relative gene expression data using realtime quantitative PCR and the 2(-Delta Delta C(T)) Method. Methods. (2001) 25:402-8. doi: 10.1006/meth.2001.1262

34. Farndale RW, Sayers CA, Barrett AJ. A direct spectrophotometric microassay for sulfated glycosaminoglycans in cartilage cultures. Connect Tissue Res. (1982) 9:247-8. doi: 10.3109/03008208209160269

35. Durgam SS, Stewart AA, Sivaguru M, Wagoner Johnson AJ, Stewart MC. Tendon-derived progenitor cells improve healing of collagenase-induced flexor tendinitis. J Orthop Res. (2016) 34:2162-71. doi: 10.1002/jor.23251

36. Caron JP, Gandy JC, Schmidt M, Hauptman JG, Sordillo LM. Influence of corticosteroids on interleukin- $1 \beta$-stimulated equine chondrocyte gene expression. Vet Surg. (2013) 42:231-7. doi: 10.1111/j.1532-950X.2012.01025.x

37. Lutter JD, Schneider RK, Sampson SN, Cary JA, Roberts GD, Vahl CI. Medical treatment of horses with deep digital flexor tendon injuries diagnosed with high-field-strength magnetic resonance imaging: 118 cases (2000-2010). J Am Vet Med Assoc. (2015) 247:1309-18. doi: 10.2460/javma.247.11.1309 
38. Maman E, Yehuda C, Pritsch T, Morag G, Brosh T, Sharfman Z, et al. Detrimental effect of repeated and single subacromial corticosteroid injections on the intact and injured rotator cuff: A biomechanical and imaging study in rats. Am J Sports Med. (2016) 44:177-82. doi: 10.1177/03635465155 91266

39. Dinhane KGI, Godoy-Santos AL, Fabro AT, Moretto MR, Deprá I, Yoshida WB. Short-term changes after corticosteroid injections into the normal tendons of rabbits: a controlled randomized study. Am J Sports Med. (2019) 47:721-8. doi: 10.1177/0363546518818819

40. Riley G. The pathogenesis of tendinopathy. A molecular perspective. Rheumatology. (2004) 43:131-42. doi: 10.1093/rheumatology/keg448

41. Muto T, Kokubu T, Mifune Y, Inui A, Harada Y, Yoshifumi Takase F, et al. Temporary inductions of matrix metalloprotease-3 (MMP-3) expression and cell apoptosis are associated with tendon degeneration or rupture after corticosteroid injection. J Orthop Res. (2014) 32:1297304. doi: 10.1002/jor.22681

42. Sendzik J, Shakibaei M, Schäfer-Korting M, Lode H, Stahlmann R. Synergistic effects of dexamethasone and quinolones on human-derived tendon cells.
Int J Antimicrob Agents. (2010) 35:366-74. doi: 10.1016/j.ijantimicag.2009. 10.009

43. Lee HJ, Kim YS, Ok JH, Lee YK, Ha MY. Effect of a single subacromial prednisolone injection in acute rotator cuff tears in a rat model. Knee Surg Sports Traumatol Arthrosc. (2015) 23:555-61. doi: 10.1007/s00167-013-2395-1

Conflict of Interest: The authors declare that the research was conducted in the absence of any commercial or financial relationships that could be construed as a potential conflict of interest.

Copyright (c) 2020 Sullivan, Altmann, Brokken and Durgam. This is an open-access article distributed under the terms of the Creative Commons Attribution License (CC $B Y)$. The use, distribution or reproduction in other forums is permitted, provided the original author(s) and the copyright owner(s) are credited and that the original publication in this journal is cited, in accordance with accepted academic practice. No use, distribution or reproduction is permitted which does not comply with these terms. 